\title{
La reparación Integral en marco doctrinario-legal y su situación en el Ecuador
}

Comprehensive repair in a doctrinal-legal framework and its situation in Ecuador

\author{
Luis Ramiro Ayala-Ayala \\ ur.luisayala@uniandes.edu.ec \\ Universidad Regional Autónoma de los Andes, Riobamba \\ Ecuador \\ https://orcid.org/0000-0003-3019-8487 \\ Juan Carlos Guamán-Anilema \\ guamanjuancarlitos@hotmail.com \\ Universidad Regional Autónoma de los Andes, Riobamba \\ Ecuador \\ Marcelo Emilio Paredes-Moreno \\ emiliop1423@gmail.com \\ Universidad Regional Autónoma de los Andes, Riobamba \\ Ecuador
}

Recibido: 31 de octubre de 2020

Revisado: 10 de octubre de 2020

Aprobado: 05 de diciembre de 2020

Publicado: 10 de diciembre de 2020 


\title{
RESUMEN
}

La presente investigación aborda una conceptualización doctrinal acerca de la reparación integral, sus mecanismos y la realidad de esta figura jurídica en Ecuador. El objetivo general de la misma es identificar los mecanismos que propende esta figura jurídica de reparación y establecer cuál es la realidad en Ecuador. Se fundamentó en el paradigma cuantitativo, tipo documental bibliográfico, por otro lado, el método específico aplicado a la investigación es el analítico-sintético, en forma de redacción; la que es captada, analizada, procesada y descrita, utilizando juicios de valor y exposición. La técnica fue la de análisis de documentos. Se concluye que la situación real de esta figura jurídica en muchos casos no se cumple, ya que estas medidas si se implementan dentro de sentencias, al momento de su ejecución no se cumplen, y llegando a determinar que la excusa para su incumplimiento en la mayoría de los casos es la pobreza de las personas que cometen el ilícito.

Descriptores: Procedimiento legal; mediación; sentencia judicial. (Palabras tomadas del Tesauro UNESCO).

\begin{abstract}
This research addresses a doctrinal conceptualization about comprehensive reparation, its mechanisms and the reality of this legal figure in Ecuador. The general objective of the same is to identify the mechanisms that this legal figure of reparation proposes and to establish what the reality is in Ecuador. It was based on the quantitative paradigm, bibliographic documentary type, on the other hand, the specific method applied to research is analytical-synthetic, in the form of writing; which is captured, analyzed, processed and described, using value judgments and exposure. The technique was document analysis. It is concluded that the real situation of this legal figure in many cases is not fulfilled, since these measures are implemented within sentences, at the time of their execution they are not fulfilled, and even determining that the excuse for their non-compliance in the majority of the cases is the poverty of the people who commit the crime.
\end{abstract}

Descriptors: Legal procedure; mediation; judicial sentence. (Words taken from the UNESCO Thesaurus). 
Luis Ramiro Ayala-Ayala; Juan Carlos Guamán-Anilema; Marcelo Emilio Paredes-Moreno

\section{INTRODUCCIÓN}

Era importante la implementación de una figura jurídica que permitiera reconocer una forma de subsanar, los efectos que deja el ser víctima de un delito, ya que muchas veces la imposición de una pena no satisface o no subsana las brechas que el delito deja a su paso. En un Estado democrático y progresista, la seguridad es un factor coadyuvante del bienestar social y de la calidad de vida. El desenvolvimiento de una nueva cultura y la concepción de la seguridad no deben estar circunscritos únicamente a la prevención o persecución del delito; deben estar orientados a promover las salvaguardas y la garantía de todos los derechos humanos. (Zambrano-Noles, 2015:65).

Con respecto a la normativa ecuatoriana, la reforma Constitucional del 2008 implementó la reparación integral que serviría como medio de reconocimiento y compensación al derecho de la persona que ha sido víctima de un ilícito. En este sentido la reparación integral es un derecho de la víctima, por lo tanto, la garantía del ejercicio de dicho derecho es responsabilidad exclusiva del Estado. La reparación es poder resarcir a la víctima por el daño ocasionado debido a la comisión de un delito, a pesar del sentido crítico que sostiene que una víctima no podrá regresar al estado anterior al de la afectación de su bien jurídico protegido. (Benavides-Benalcázar,2019: 419)

Podemos afirmar entonces que la reparación integral no son más que medidas que tienen el fin de hacer desaparecer o de enmendar los efectos que la víctima de un ilícito ha sufrido. Otro elemento es la responsabilidad de las partes en asumir la responsabilidad, respetando las normas jurídicas, el respeto por el principio de igualdad es una de las garantías más importantes que se deben perseguir en el juicio de responsabilidad, de manera que las decisiones judiciales deben preocuparse por guardar uniformidad y coincidencia en casos similares, aspecto que no acontece en la experiencia colombiana donde las disparidades son notables. (Sandoval-Garrido, 2013: 263). 
Persiguiendo el objetivo mencionado en líneas anteriores, la reparación integral establece mecanismos que han sido regulados por la legislación ecuatoriana, al referirnos a mecanismos se hace alusión a ciertos elementos que se deben aplicar para ejecutar una acción determinada, los mismos que se encuentran enmarcados en la Constitución de la República del Ecuador, la Ley Orgánica de Garantías Jurisdiccionales y Control Constitucional (LOGJCC) y describiendo las acciones que establece cada uno de estos mecanismos dentro del Código Orgánico Integral Penal (COIP).

En este sentido, el artículo 6 de la Ley Orgánica de Garantías Jurisdiccionales y Control Constitucional

Finalidad de las garantías. - Las garantías jurisdiccionales tienen como finalidad la protección eficaz e inmediata de los derechos reconocidos en la Constitución y en los instrumentos internacionales de derechos humanos, la declaración de la violación de uno o varios derechos, así como la reparación integral de los daños causados por su violación.

Las medidas cautelares tienen como finalidad prevenir, impedir o interrumpir la violación de un derecho.

Salvo los casos en que esta ley dispone lo contrario, la acción de protección, el hábeas corpus, la acción de acceso a la información pública, el hábeas data, la acción por incumplimiento, la acción extraordinaria de protección y la acción extraordinaria de protección contra decisiones de la justicia indígena, se regulan de conformidad con este capítulo.

Así mismo el Artículo. 9.- Legitimación activa. - Las acciones para hacer efectivas las garantías jurisdiccionales previstas en la Constitución y esta ley, podrán ser ejercidas: a) Por cualquier persona, comunidad, pueblo, nacionalidad o colectivo, vulnerada 0 amenazada en uno o más de sus derechos constitucionales, quien actuará por sí misma o a través de representante o apoderado; $y$,

b) Por el Defensor del Pueblo. 
Se consideran personas afectadas quienes sean víctimas directas o indirectas de la violación de derechos que puedan demostrar daño. Se entenderá por daño la consecuencia o afectación que la violación al derecho produce.

En el caso de las acciones de hábeas corpus y extraordinaria de protección, se estará a las reglas específicas de legitimación que contiene esta ley.

Por lo tanto, la reparación consagrada en las leyes ecuatorianas en un sentido amplio busca de acuerdo a Aguirre-Castro \& Alarcón Peña (2018):

La reparación integral surge como consecuencia jurídica de la vulneración de un derecho por la que se exige a su vez la responsabilidad del agresor. Esta premisa permite afirmar inequívocamente que toda persona que se vea afectada en sus derechos ilegítimamente tiene derecho a exigir la reparación del daño. Este carácter de exigibilidad que impregna a la reparación integral la convierte en un derecho individual y colectivo, cuando deviene de la transgresión de un derecho humano/fundamental/constitucional. (p.124)

Sin embargo, al hablar de la situación actual de esta figura en Ecuador según algunos casos valorados y expuestos por medios de información, victimas aseguran que estas medidas de reparación integral se encuentran presentes en la normativa ecuatoriana pero que sin embargo no se cumplen. Pero es de carácter obligatorio y norma de fiel cumplimento lo establecido en la legislación del Estado. Por ello, una norma jurídica pertenece a un ordenamiento jurídico cuando, de acuerdo con los criterios de identificación existentes, se puede afirmar que hace parte de él. Por otra parte, una norma es aplicable cuando el derecho exige que los órganos decisores le otorguen autoridad con respecto a un caso. (Mercado-Donato \& Rojas-Pinzón,2015:82)

En base a lo descrito, la importancia de este trabajo se plantea en entender a la reparación integral y a la situación que ha rodeado a esta figura en el Ecuador, el objetivo general de la investigación es identificar los mecanismos que propende esta figura jurídica de reparación y establecer cuál es la realidad en Ecuador. 


\section{METODOLOGÍA}

La presente investigación se fundamentó en el paradigma cuantitativo, tipo documental bibliográfico, por otro lado, el método específico aplicado a la investigación es el analítico-sintético, ya que permite que una serie de información se sintetice en forma de redacción; la que es captada, analizada, procesada y descrita, utilizando juicios de valor y exposición, sin dejar de lado el análisis con un criterio personal. Descriptiva, ya que esta consiste en la descripción de las características de una figura jurídica partiendo de hechos, conceptos y métodos a fin poder identificar su esencia y características. La técnica que se va a utilizar en esta investigación es la de análisis de documentos, siendo una técnica efectiva de adquisición y recopilación de información.

\section{RESULTADOS}

\section{Nociones doctrinales de la reparación integral}

Era necesario que se reconozca una forma de compensar a todas aquellas personas que alguna vez han sido víctima de un delito, ya que en muchos casos la imposición de una pena sobre una persona que ha cometido un delito es insuficiente para resarcir los daños materiales e inmateriales que este deja en la víctima y en su ausencia, en sus familiares. Dentro de la legislación ecuatoriana la reforma constitucional de 2008 trajo consigo nuevas figuras jurídicas que el sistema ecuatoriano no contemplaba, entre estas la reparación integral misma que reconocería y garantizaría el derecho de aquellas personas que en algún momento fueron mártires de transgresiones penales, a que se subsanen los daños causados por el cometimiento del ilícito.

La reparación integral se enmarca en un contexto jurídico muy amplio siendo abordada, de manera nacional e internacional, es aquí donde cabe mencionar que esta figura jurídica trae consigo varias concepciones a nivel doctrinario que nos permitirán tener una mejor conceptualización de esta figura, y que, además nos ayudarán a entender de mejor manera su esencia. 
El profesor Merck Benavides, ex-juez de la sala de lo laboral de la Corte Nacional de Justicia menciona lo siguiente:

La reparación integral involucra aquellas medidas destinadas a hacer desaparecer los efectos de las violaciones cometidas y a indemnizarlas. Se trata de reparar los daños a la víctima, sean estos materiales e inmateriales, patrimoniales y hasta familiares, procura implementar diferentes formas de reparación; en Ecuador la reparación integral es un derecho de rango constitucional y legal (Benavides-Benalcázar, 2019).

Para la Organización de las Naciones Unidas:

En la declaración de los Derechos Humanos adoptada por la Asamblea General de las Naciones Unidas, el derecho a la reparación se encuentra legislado en el artículo 8 en la que se consagra que: "uno de los derechos de carácter personal es que todas las personas tienen derecho a que los jueces las traten de forma justa cuando existan actos que violen sus derechos fundamentales reconocidos por la Constitución o por la ley" (Organización de Naciones Unidas, 1948:45).

Continuando con esta línea, la Convención Americana de Derechos Humanos, suscrita en San José, Costa Rica del 7 al 22 de noviembre de 1969, en el artículo 63 numeral 1) establece que:

Cuando decida que hubo violación de un derecho o libertad protegidos en esta Convención, la Corte dispondrá que se garantice al lesionado en el goce de su derecho o libertad conculcados. Dispondrá, asimismo, si ello fuera procedente, que se reparen las consecuencias de la medida 0 situación que ha configurado la vulneración de esos derechos y el pago de una justa indemnización a la parte lesionada (Organizacion de Estados Americanos , 1962: 13).

Ante estas posturas, la legislación ecuatoriana ha tomado en cuenta esta figura jurídica de gran importancia en el saneamiento de los daños ocasionados hacia la víctima de una infracción penal.

Es así como, la Constitución del Ecuador en el artículo 78 determina que: 
Las víctimas de infracciones penales gozarán de protección especial, se les garantizará su no revictimización, particularmente en la obtención y valoración de las pruebas, y se las protegerá de cualquier amenaza u otras formas de intimidación. Se adoptarán mecanismos para una reparación integral que incluirá, sin dilaciones, el conocimiento de la verdad de los hechos y la restitución, indemnización, rehabilitación, garantía de no repetición y satisfacción del derecho violado. (Constitución de la República del Ecuador , 2008:57)

Seguidamente, la Ley Orgánica de Garantías Jurisdiccionales y Control Constitucional en el artículo 18 establece que:

Reparación integral. - En caso de declararse la vulneración de derechos se ordenará la reparación integral por el daño material e inmaterial. La reparación integral procurará que la persona o personas titulares del derecho violado gocen y disfruten el derecho de la manera más adecuada posible y que se restablezca a la situación anterior a la violación (...) (Ley Orgánica de Garantías Jurisdiccionales y Control Constitucional, 2009: 9).

Por último, dentro del marco penal ecuatoriano vigente, el Código Orgánico Integral Penal en el artículo 77 plantea que: La reparación integral radicará en la solución que objetiva y simbólicamente restituya, en la medida de lo posible, al estado anterior de la comisión del hecho y satisfaga a la víctima, cesando los efectos de las infracciones perpetradas (...) (Código Orgánico Integral Penal, 2014: 29)

La reparación integral es así entendida como el conjunto de todas aquellas medidas que prosiguen, el fin de hacer desaparecer los efectos producidos o que se desencadenaron a raíz de la comisión de una infracción penal.

\section{Mecanismos para la reparación integral}

Al hablar de mecanismos, se idealiza a aquellos elementos o instrumentos necesarios para la efectiva ejecución o desarrollo de una actividad determinada.

Partiendo de la idea expuesta, al hablar acerca de mecanismos de reparación integral, podemos inferir que se hace referencia a elementos, instrumentos o componentes fundamentales en atención a resarcir el daño producido en una persona, víctima del cometimiento de un delito. 
La legislación ecuatoriana establece estos mecanismos de reparación, es así como la Constitución del Ecuador en el artículo 78 reconoce la reparación integral de la víctima, estableciendo también ciertos mecanismos que garantizan la ejecución de este derecho de la víctima por parte del victimario al establecer que:

Art. 78.- (...). Se adoptarán mecanismos para una reparación integral que incluirá, sin dilaciones, el conocimiento de la verdad de los hechos y la restitución, indemnización, rehabilitación, garantía de no repetición y satisfacción del derecho violado (Constitución de la República del Ecuador , 2008:57).

En la misma línea, la Ley orgánica de Garantías Jurisdiccionales y Control Constitucional, también se pronuncia con respecto de estos mecanismos en su artículo 18.

(...). La reparación podrá incluir, entre otras formas, la restitución del derecho, la compensación económica o patrimonial, la rehabilitación, la satisfacción, las garantías de que el hecho no se repita, la obligación de remitir a la autoridad competente para investigar y sancionar, las medidas de reconocimiento, las disculpas públicas, la prestación de servicios públicos, la atención de salud (Ley Orgánica de Garantías Jurisdiccionales y Control Constitucional, 2009: 9).

Continuando, dentro del marco penal ecuatoriano, el Código Orgánico Integral Penal (COIP) en el artículo 78 expone y explica cada uno de estos mecanismos, estableciendo que:

Artículo 78.- Mecanismos de reparación integral. - Las formas no excluyentes de reparación integral, individual o colectiva, son:

1. La restitución: se aplica a casos relacionados con el restablecimiento de la libertad, de la vida familiar, de la ciudadanía o de la nacionalidad, el retorno al país de residencia anterior, la recuperación del empleo o de la propiedad, así como al restablecimiento de los derechos políticos.

2. La rehabilitación: se orienta a la recuperación de las personas mediante la atención médica y psicológica, así como a garantizar la prestación de servicios jurídicos y sociales necesarios para esos fines. 
3. Las indemnizaciones de daños materiales e inmateriales: se refieren a la compensación por todo perjuicio que resulte como consecuencia de una infracción penal y que sea evaluable económicamente.

4. Las medidas de satisfacción o simbólicas: se refieren a la declaración de la decisión judicial de reparar la dignidad, la reputación, la disculpa y el reconocimiento público de los hechos y de las responsabilidades, las conmemoraciones y los homenajes a las víctimas, la enseñanza y la difusión de la verdad histórica.

5. Las garantías de no repetición: se orientan a la prevención de infracciones penales y a la creación de condiciones suficientes para evitar la repetición de las mismas. Se identifican con la adopción de las medidas necesarias para evitar que las víctimas sean afectadas con la comisión de nuevos delitos del mismo género (Código Orgánico Integral Penal, 2014:30).

\section{DISCUSIÓN}

La reparación integral son un conjunto de mecanismos que buscan, a través de la aplicación de estos, subsanar, minimizar los efectos, entre otros, que el cometimiento de un ilícito deja en la victima de este hecho. Gracias a la legislación vigente y en concordancia con las normas internacionales y acuerdos firmados por el Estado Ecuatoriano, contribuye al ejercicio de la profesión de abogado y juez, en medio de un mundo convulsionado.

\section{CONCLUSIONES}

Una vez conocida la conceptualización que tienen varios jurisconsultos acerca del tema y una vez que se revisó la normativa ecuatoriana, se entendió que la reparación integral consiste en el conjunto de todas aquellas medidas que prosiguen el fin de hacer desaparecer los efectos producidos o que se desencadenaron a raíz de la comisión de un ilícito, asegurando de esta manera el pleno ejercicio y disfrute de su derecho. 
La investigación facilito el conocimiento de las medidas que se establecen dentro de la reparación integral, mismas que se encuentran establecidas en la Constitución de la República del Ecuador, la LOGJCC y el COIP y detallándolas a breves rasgos son: Las garantías de no repetición, Las medidas de satisfacción o simbólicas, Las indemnizaciones de daños materiales e inmateriales, la rehabilitación y la restitución. Se determinó a través de esta investigación que la situación real de esta figura jurídica en muchos casos no se cumple, ya que estas medidas si se implementan dentro de sentencias, sin embargo, al momento de su ejecución no se cumplen, y llegando a determinar que la excusa para su incumplimiento en la mayoría de los casos es la pobreza de las personas que cometen el ilícito.

\section{FINANCIAMIENTO}

No monetario.

\section{AGRADECIMIENTO}

A la Universidad Regional Autónoma de Los Andes; por motivar el desarrollo de la Investigación.

\section{REFERENCIAS CONSULTADAS}

Aguirre Castro, P., \& Alarcón Peña, P. (2018). El estándar de la reparación integral en la jurisprudencia de la Corte Constitucional. [The standard of comprehensive reparation in the jurisprudence of the Constitutional Court]. Foro, Revista De Derecho, (30), 121-143. https://doi.org/10.32719/26312484.2018.30.8

Asamblea Nacional Constituyente de la República del Ecuador, (2008). Constitución de la República del Ecuador. Montecristi. Registro Oficial 449 de 20-oct-2008. Recuperado de https://n9.cl/sia

Asamblea Nacional Constituyente de la República del Ecuador, (2009). Ley Orgánica de Garantías Jurisdiccionales y Control Institucional. [Organic Law on Jurisdictional Guarantees and Institutional Control]. Registro Oficial suplemento 52 de 22-oct-2009. Recuperado de: https://n9.cl/su7v 
Luis Ramiro Ayala-Ayala; Juan Carlos Guamán-Anilema; Marcelo Emilio Paredes-Moreno

Asamblea Nacional de la República del Ecuador. (2014). Código Orgánico Integral Penal. [Comprehensive Organic Criminal Code]. Recuperado de https://n9.cl/g6sc

Benavides-Benalcázar, M. (2019). La reparación integral de la víctima en el proceso penal. [Comprehensive redress of the victim in criminal proceedings] Universidad $y$ Sociedad, 11(5),410-420. Recuperado de http://rus.ucf.edu.cu/index.php/rus

Mercado-Donato, M. \& Rojas-Pinzón, J. (2015) Discusiones contemporáneas sobre derechos humanos en el marco de la globalización. Desafíos conceptuales del bloque constitucional. [Contemporary discussions on human rights within the framework of globalization. Conceptual challenges of the building block]. Universidad del Rosario. https://doi.org/10.7476/9789587386714.

Organización de Estados Americanos. Convención Americana sobre Derechos Humanos. [American Convention on Human Rights]. (Pacto de San José) (Gaceta Oficial No. 9460 del 11 de febrero de1978). Recuperado de: https://n9.cl/780p

Organización de Naciones Unidas. (10 de diciembre de 1948). Declaración. Declaración Universal de los Derechos Humanos. [Statement. Universal Declaration of Human Rights], Whashintong, Estados Unidos: ONU.

Sandoval- Garrido, A. (2013) Reparación integral y responsabilidad civil: el concepto de reparación integral y su vigencia en los daños extrapatrimoniales a la persona como garantía de los derechos de las víctimas. [Comprehensive repair and civil liability: the concept of comprehensive reparation and its validity in extramarital damage to the person as a guarantee of the rights of the victims]. Derecho Privado, 25,235-271. Recuperado de: http://www.scielo.org.co/pdf/rdp/n25/n25a10.pdf

Zambrano-Noles, S. (2016). El acceso a la justicia y la tutela judicial efectiva en relación con la seguridad Ciudadana en Ecuador. [Access to justice and effective judicial protection in relation to citizen security in Ecuador]. Tla-Melaua, 9(39),58-78. Recuperado de https://n9.cl/2cu8 